Article

\title{
Sarmentosamide, an Anti-Aging Compound from a Marine-Derived Streptomyces sp. APmarine042
}

\author{
Eun-Soo Lee ${ }^{1,+} \oplus$, Eun-Young Lee ${ }^{2,+}$, Jisoo Yoon ${ }^{2}$, Ahreum Hong ${ }^{3}$, Sang-Jip Nam ${ }^{2, *}$ and \\ Jaeyoung Ko ${ }^{1, *(D)}$ \\ 1 Amorepacific Corporation R\&D Center, Yongin 17074, Korea; soopian82@gmail.com \\ 2 Department of Chemistry and Nanoscience, Ewha Womans University, Seoul 03760, Korea; \\ younglee0124@naver.com (E.-Y.L.); jisoo87@naver.com (J.Y.) \\ 3 Graduate School of Industrial Pharmaceutical Sciences, Ewha Womans University, Seoul 03760, Korea; \\ lyzenne@naver.com \\ * Correspondence: sjnam@ewha.ac.kr (S.-J.N.); jaeyoungko@amorepacific.com (J.K.); \\ Tel.: +82-2-3277-6805 (S.-J.N.); +82-31-280-5928 (J.K.) \\ + These authors contributed equally to this work.
}

Received: 8 August 2020; Accepted: 8 September 2020; Published: 10 September 2020

\begin{abstract}
Many bioactive materials have been isolated from marine microorganisms, including alkaloids, peptides, lipids, mycosporine-like amino acids, glycosides, and isoprenoids. Some of these compounds have great potential in the cosmetic industry due to their photo-protective, anti-aging, and anti-oxidant activities. In this study, sarmentosamide (1) was isolated from marine-derived Streptomyces sp. APmarine042, after which its capacity to decrease skin aging was examined in-vitro. Sarmentosamide (1) was found to significantly reduce UVB-induced matrix metalloproteinase-1 (MMP-1) expression in normal human dermal fibroblasts (NHDFs) by inhibiting the extracellular signal-regulated kinase (ERK) and the c-Jun N-terminal kinase (JNK) phosphorylation, which are regulatory pathways upstream of MMP-1 transcription. Additionally, we confirmed that sarmentosamide (1) decreased tumor necrosis factor-alpha (TNF- $\alpha$ ), induced MMP-1 secretion in NHDFs, and exhibited free-radical scavenging activity, as demonstrated by 2,2-diphenyl-1-picrylhydrazyl (DPPH) assay. Therefore, our study suggests that sarmentosamide (1) could be a promising anti-aging agent that acts via the downregulation of MMP-1 expression.
\end{abstract}

Keywords: sarmentosamide; Streptomyces sp. APmarine042; anti-aging; MMP-1; UVB; TNF- $\alpha$

\section{Introduction}

Skin aging is induced by two main processes, which result from intrinsic and extrinsic factors. Extrinsic aging is primarily caused by exposure to environmental factors such as air pollution [1] and ultraviolet (UV) radiation [2]. UV light is composed of UVA (315-400 nm), UVB (280-315 nm), and UVC (200-280 nm), of which UVB rays are known to penetrate the epidermis and contribute to skin photoaging [3]. UVB-induced skin photoaging causes DNA damage [4] and reactive oxygen species (ROS) generation [5] and disrupts the extracellular matrix [6]. Intrinsic aging is caused by the natural consequences of physiological change, such as genetic factors, hormones, and metabolic processes [7]. Moreover, inflammatory cytokines, such as tumor necrosis factor-alpha (TNF $\alpha)$, interleukin 1 alpha/beta (IL-1 $\alpha / \beta)$, and interleukin 6 (IL-6), are chronically increased with age. In particular, tumor necrosis factor- $\alpha(\mathrm{TNF} \alpha)$ is known to accelerate the degradation of extracellular matrix (ECM) components via upregulating expression and activity of matrix metalloproteinases (MMPs) in aged skin [8]. MMP-1 is mainly released by fibroblasts in the dermis, and secreted MMP-1 is responsible for the degradation of dermal collagen, which supports skin structure and function. Therefore, modulation of MMP-1 
expression in dermal fibroblasts could be a promising target for the development of anti-aging cosmetic ingredients.

Previous studies have reported that UVB radiation induces ROS (reactive oxygen species) production and leads to the activation of intracellular signaling pathways and transcription factors (e.g., AP-1, NF-kB) [9]. These transcription factors are regulated by mitogen-activated protein kinases (MAPKs), which induce MMP-1 and proinflammatory cytokines. There are three distinct MAPK families involved in UVB/ROS stimuli: extracellular signal-regulated kinases (ERKs), c-Jun N-terminal kinase (JNK), and p38.

Our study identified a Streptomyces sp. APmarine042 extract that exhibited a potent inhibitory effect on MMP-1 expression. Afterward, an MMP-1 inhibitory compound was identified in this Streptomyces sp. APmarine042 extract, and its chemical structure was identified via NMR analyses as sarmentosamide (1), a compound with a hexadienamide moiety [10]. We then further investigated whether this compound inhibited MMP-1 expression in UVB-irradiated and TNF $\alpha$-induced human dermal fibroblasts as well as its role in the regulation of underlying signaling pathways. Additionally, we examined the antioxidant activity of sarmentosamide (1) via a 2,2-diphenyl-1-picrylhydrazyl $(\mathrm{DPPH})$ radical scavenging assay.

\section{Results and Discussion}

\subsection{Sarmentosamide (1) Isolation and Identification}

Sarmentosamide (1) was isolated through a combination of HPLC-UV and bioactivity-guided isolation. Based on the comparison between the NMR data (Supplementary Materials) of the compound identified in this study (hereinafter referred to as "compound 1") to those of previously reported compounds, compound $\mathbf{1}$ was identified as sarmentosamide. The optical rotation value of compound $\mathbf{1}$ was also consistent with previous reports, which further supported that compound $\mathbf{1}$ was sarmentosamide (Figure 1).

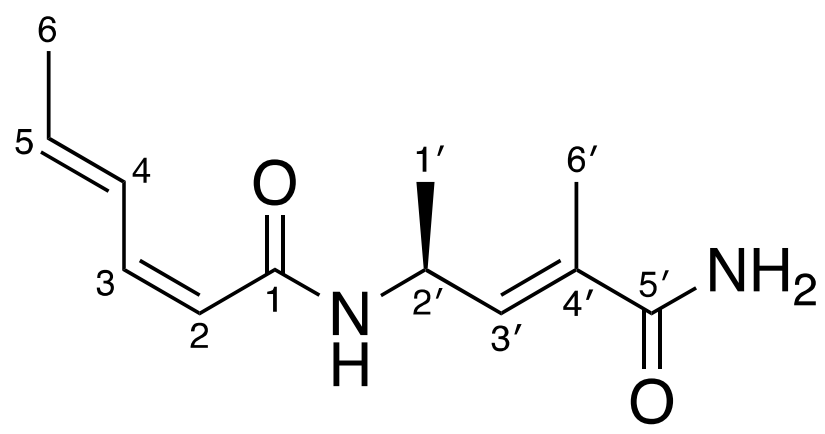

1

Figure 1. Chemical structure of sarmentosamide (1).

\subsection{Cytotoxic Effects of Sarmentosamide (1) on Human Dermal Fibroblasts}

To investigate the cytotoxic effects of sarmentosamide, normal human dermal fibroblasts (NHDF) or human foreskin fibroblast cells (Hs68) were treated with sarmentosamide at different concentrations $(6,12,25,50,100 \mu \mathrm{g} / \mathrm{mL})$ for $24 \mathrm{~h}$, after which the cell counting kit-8 (CCK-8) assay was performed to quantify cell viability. Water-soluble tetrazolium salt (WST-8) in CCK-8 solution was reduced by dehydrogenase activities in cells to give a yellow-color formazan dye, the amount of which was proportional to the number of living cells. As shown in Figure 2, sarmentosamide did not cause any observable cytotoxic effects in either NHDF or Hs68 cells at concentrations ranging from 0-100 $\mu \mathrm{g} / \mathrm{mL}$. 

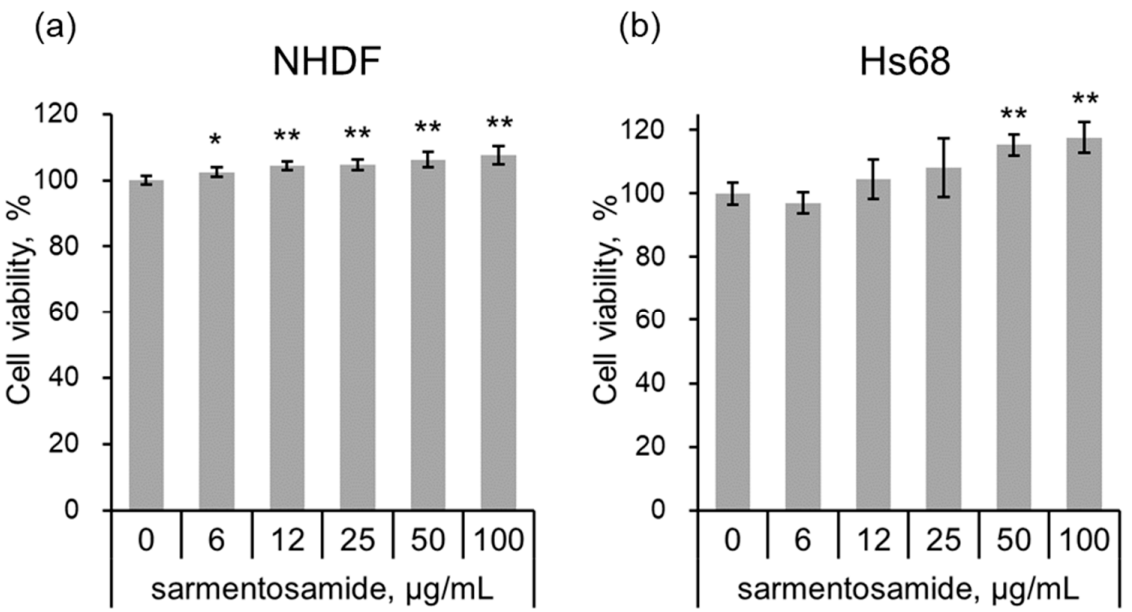

Figure 2. Cell viability test of sarmentosamide on fibroblasts. (a,b) The cell viability of sarmentosamide-treated normal human dermal fibroblasts (NHDF) (a) and human foreskin fibroblast cells (Hs68) (b) cells at $24 \mathrm{~h}$ was measured by CCK (cell counting kit) assay. ${ }^{*} p<0.05 ;{ }^{* *} p<0.01$ (vs. untreated group).

\subsection{Sarmentosamide (1) Inhibits MMP-1 Expression and Secretion in UVB-Irradiated NHDF Cells}

Next, NHDFs in the absence and the presence of UVB radiation $\left(25 \mathrm{~mJ} / \mathrm{cm}^{2}\right)$ were treated with sarmentosamide $(2.5 \mu \mathrm{g} / \mathrm{mL})$ for short periods, and relative MMP-1 mRNA expression levels were quantified via quantitative real-time PCR analysis. Sarmentosamide was found to downregulate MMP- 1 mRNA levels by up to $16 \%$ and $17 \%$ in the absence (Figure $3 a$ ) and the presence (Figure $3 b$ ) of UVB, respectively. UVB radiation, a major extrinsic skin aging risk factor, can penetrate the epidermis and reach the upper dermis, resulting in the generation of reactive oxygen species (ROS), MMP production, and collagen synthesis downregulation. Therefore, our study sought to investigate whether sarmentosamide inhibited MMP-1 secretion in UVB-irradiated NHDF cells. The secretion levels of MMP- 1 in cell culture media were measured via ELISA, and the relative amounts of MMP-1 secretion were normalized to total protein in whole cell lysates, which were measured via a bicinchoninic acid (BCA) protein quantification assay. UVB irradiation $\left(25 \mathrm{~mJ} / \mathrm{cm}^{2}\right)$ remarkably increased MMP-1 secretion (8.3-fold) compared to the non-UVB-irradiated group (Figure 3c) and sarmentosamide inhibited MMP-1 secretion in UVB-irradiated NHDF cells in a dose-dependent manner.

(a)

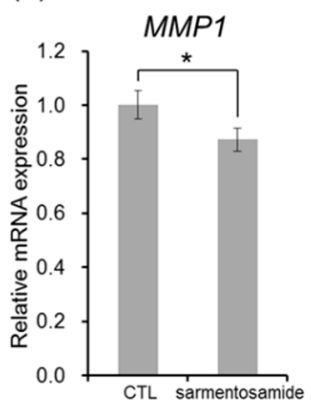

(b)

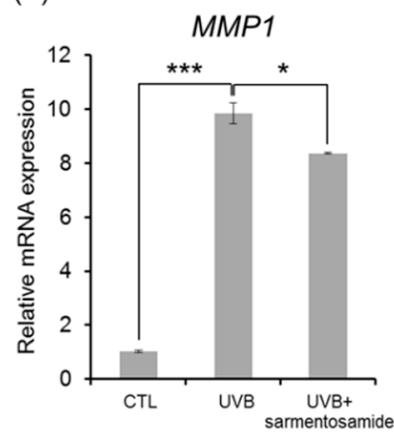

(c)

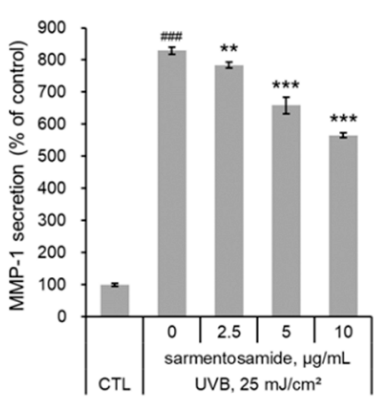

Figure 3. Effect of sarmentosamide on metalloproteinase-1 (MMP-1) expression in UVB-irradiated NHDFs. $(\mathbf{a}, \mathbf{b})$ The relative mRNA levels of MMP-1 in NHDF cells irradiated UVB $\left(25 \mathrm{~mJ} / \mathrm{cm}^{2}\right)$ or treated with sarmentosamide $(2.5 \mu \mathrm{g} / \mathrm{mL})$ for $16 \mathrm{~h}$. RPLP0 gene was used as an internal control. ${ }^{*} p<0.05$; $* * * p<0.001$ (c) After UVB irradiation $\left(25 \mathrm{~mJ} / \mathrm{cm}^{2}\right)$, sarmentosamide in serum-free media was treated for $48 \mathrm{~h}$, and then the relative secretion levels of MMP-1 into cell culture media were analyzed by ELISA. \#\#\# $p<0.001$ (vs. non-UVB control group); ${ }^{* *} p<0.01 ;{ }^{* * *} p<0.001$ (UVB-irradiated control group). 


\subsection{Sarmentosamide (1) Downregulates JNK and ERK Phosphorylation in UVB-Irradiated NHDF Cells}

UVB radiation induces MMP-1 gene transcription by triggering the MAPK signaling pathway via the phosphorylation of JNK, ERK, and p38 signaling cascades [3]. In the NHDF cells used in this study, we confirmed that UVB induced JNK, ERK, and p38 phosphorylation in a time dependent manner. As shown in Figure 4a, MAPK phosphorylation levels reached a peak at 15 min. Therefore, to examine whether sarmentosamide attenuates UVB induced MAPK phosphorylation, NHDFs were pretreated with sarmentosamide for $24 \mathrm{~h}$ and irradiated with UVB $\left(25 \mathrm{~mJ} / \mathrm{cm}^{2}\right)$. After $15 \mathrm{~min}$ post-irradiation, the phosphorylation levels of three different MAPK proteins were measured via western blot. Our results demonstrated that sarmentosamide decreased the levels of phospho-JNK and phospho-ERK but not phospho-p38 in a dose-dependent manner (Figure 4b).

(a)

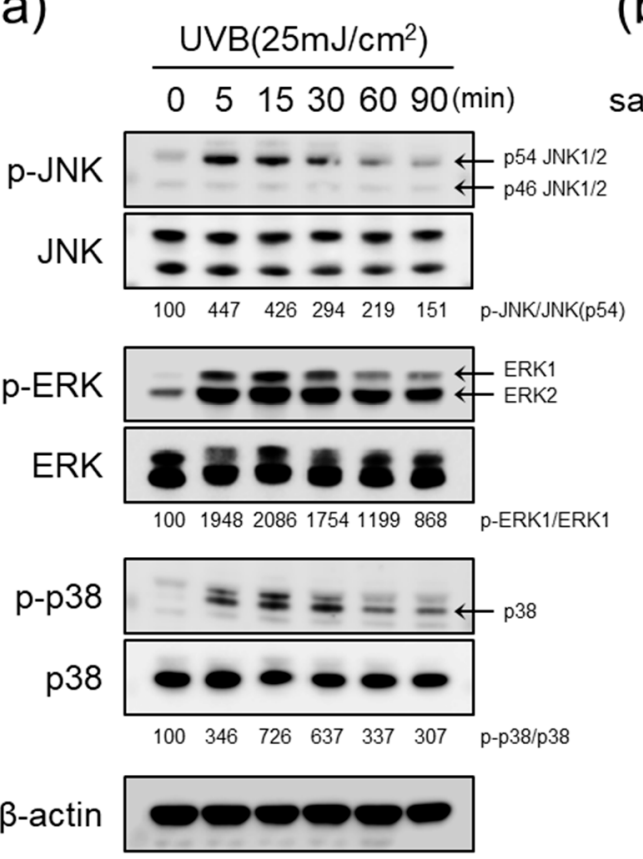

(b)
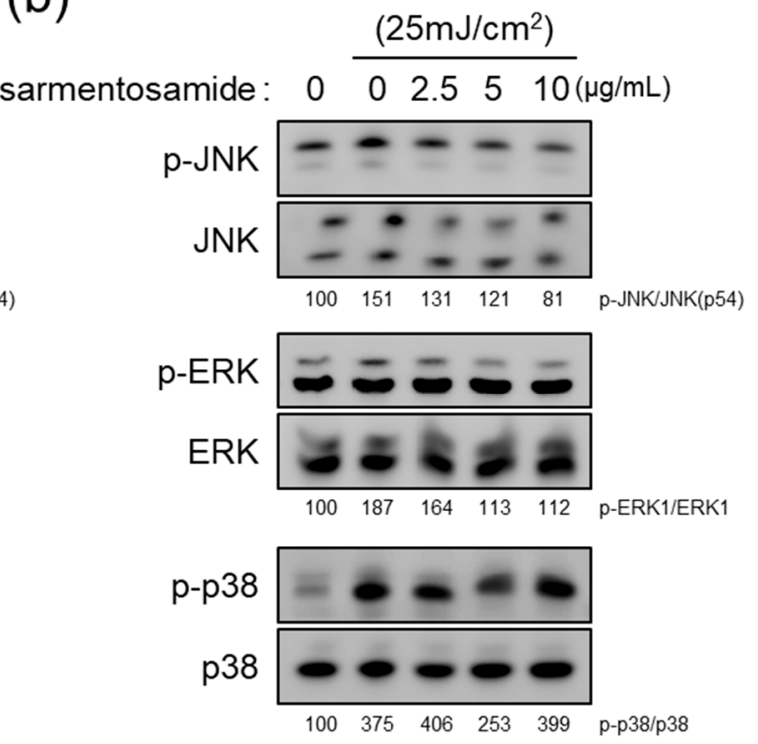

$\beta$-actin

Figure 4. Inhibitory effect of sarmentosamide on mitogen-activated protein kinases (MAPK) signaling pathway activation in UVB-irradiated NHDF cells. (a) Western blot analysis of MAPK (c-Jun N-terminal kinase (JNK), extracellular signal-regulated kinase (ERK), and p38) signaling pathway time-kinetics after UVB $\left(25 \mathrm{~mJ} / \mathrm{cm}^{2}\right)$ exposure. (b) NHDFs were pretreated with sarmentosamide at the different concentrations for $24 \mathrm{~h}$. The cells were then harvested for western blot analysis at $15 \mathrm{~min}$ post-UVB irradiation $\left(25 \mathrm{~mJ} / \mathrm{cm}^{2}\right)$. Densitometric quantification results for relative ratios of band intensities of phosphor-MAPK/total-MAPK were inserted in figure.

\subsection{Sarmentosamide (1) Inhibits MMP-1 Secretion in TNF $\alpha$-Treated NHDF Cells}

In addition to external stimuli (e.g., UV irradiation), intrinsic stimuli such as inflammatory cytokines can induce MMP-1 production. The proinflammatory cytokine TNF $\alpha$ is known to induce MMP-1 expression in dermal fibroblasts [8]. Therefore, we further investigated whether sarmentosamide downregulated MMP-1 secretion in TNF $\alpha$-induced NHDF cells. As shown in Figure 5a, TNF $\alpha(20 \mathrm{ng} / \mathrm{mL})$ upregulated MMP-1 secretion in NHDFs by up to 9.4-fold compared to the untreated control group. Treatment with sarmentosamide for $48 \mathrm{~h}$ downregulated TNF $\alpha$-induced MMP-1 secretion in a dose-dependent manner. Specifically, the inhibitions of TNF $\alpha$-induced MMP-1 secretion by sarmentosamide treatment at 2.5, 5, and $10 \mu \mathrm{g} / \mathrm{mL}$ were $24 \%, 33 \%$, and $42 \%$, respectively. 
(a)

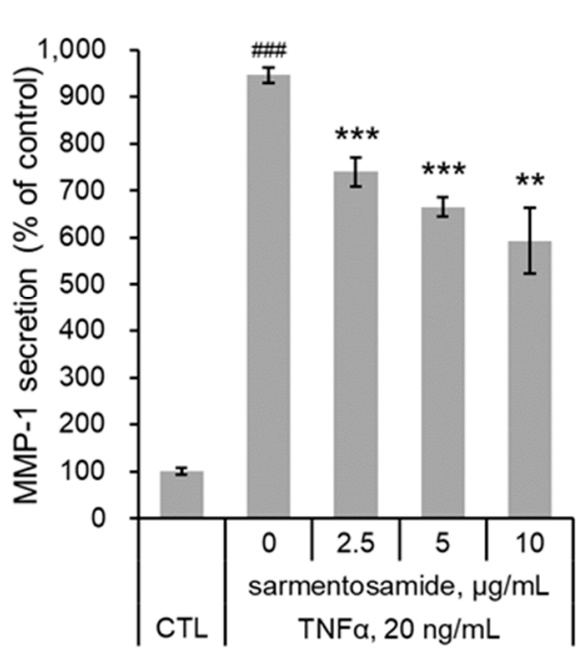

(b)

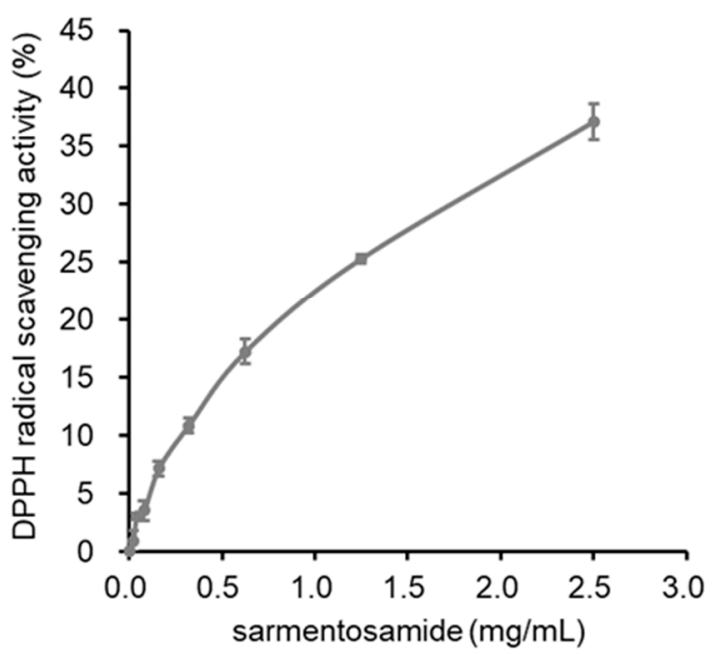

Figure 5. Protective effect of sarmentosamide on tumor necrosis factor-alpha (TNF $\alpha$ )-induced skin aging. (a) Cells were co-treated with TNF $\alpha(20 \mathrm{ng} / \mathrm{mL})$ and sarmentosamide in serum-free media for $48 \mathrm{~h}$, after which the relative secretion levels of MMP-1 in cell culture media were analyzed via ELISA. \#\#\# $p<0.001$ (relative to the TNF $\alpha$-untreated control group); ${ }^{* *} p<0.01$; ${ }^{* * *} p<0.001$ (TNF $\alpha$-treated control group). (b) The free radical scavenging activity of sarmentosamide was measured via the 2,2-diphenyl-1-picrylhydrazyl (DPPH) assay.

\subsection{Antioxidant Effect of Sarmentosamide (1) on DPPH Radical Scavenging}

Reactive oxygen species (ROS) activate AP-1 [11] and NF- $\mathrm{kB}$ [12] under inflammatory conditions and disturb the cellular redox balance. Upon exposure to the inflammatory cytokine TNF $\alpha$, cells not only activate MAPK signaling but also intracellular ROS production, resulting in a positive feedback that accelerates AP-1- and NF-KB-mediated MMP-1 expression [13]. Therefore, reducing ROS generation mitigates TNF $\alpha$-mediated skin aging. As shown in Figure 5b, upon evaluating the antioxidant capacity of sarmentosamide via a DPPH assay, this compound was found to possess a remarkable radical scavenging activity.

\section{Materials and Methods}

\subsection{General Experimental Procedures}

Extracts isolation was conducted by binary HPLC (high-performance liquid chromatography) pump (HPLC WATERS ${ }^{\mathrm{TM}}$ 600, Milford, MA, USA) coupled with a WATERS 996 photodiode array (PDA) UV/Vis detector and the reversed-phase semi-prep HPLC isolation condition (Phenomenex Luna $5 \mu \mathrm{C} 18$ column, $250 \mathrm{~mm} \times 10 \mathrm{~mm}, 5 \mu \mathrm{m}$, eluting with $40 \% \mathrm{CH}_{3} \mathrm{CN}$ at flow rate $2.0 \mathrm{~mL} / \mathrm{min}$ ). ESI (electrospray ionization) low-resolution LC-MS data were obtained with an Agilent Technologies 6120 quadrupole mass system (Agilent Technologies, Santa Clara, CA, USA) coupled with an Agilent Technologies 1260 series HPLC with a reversed-phase Phenomenex luna C18 column $(4.6 \mathrm{~mm} \times 100 \mathrm{~mm}, 5 \mu \mathrm{m})$ at a low flow rate of $1.0 \mathrm{~mL} / \mathrm{min}$. NMR spectra were acquired by Bruker Avance $300 \mathrm{MHz}$ and $150 \mathrm{MHz}$ spectrometers (Bruker Biospin Group, Karlsruhe, Germany) using methanol- $d_{4}$ as a solvent, which was purchased from Cambridge Isotope Laboratories, Inc. (Tewksbury, MA, USA). For extract fractionation, first grade solvents were acquired from Dae-Jung chemicals \& Metals Co. Ltd. For LC-MS and HPLC analyses, HPLC-grade solvents were provided from J.T.Baker. and Dae-Jung chemicals \& Metals Co. Ltd. (Sheung-Si, Korea). 


\subsection{Bacterial Strain}

The APmarine042 strain was isolated from marine-derived sediment obtained in choupori sinan goon, Jeollannam-do, South Korea, in 2013. Based on 16 s rRNA gene sequence analyses, the strain was identified as a member of the genus Streptomyces, sharing the highest identity $(99.9 \%)$ with Streptomyces coelicolor.

\subsection{Fermentation and Extraction}

Streptomyces sp. APmarine 042 was cultured in $40 \mathrm{~L}$ and $2.5 \mathrm{~L}$ Ultra Yield Flasks, each containing $1 \mathrm{~L}$ of the seawater-based medium $\left(10 \mathrm{~g} / \mathrm{L}\right.$ of soluble starch, $4 \mathrm{~g} / \mathrm{L}$ of yeas, $2 \mathrm{~g} / \mathrm{L}$ of peptone, $10 \mathrm{~g} / \mathrm{L}$ of $\mathrm{CaCO}_{3}$, $20 \mathrm{~g} / \mathrm{L}$ of $\mathrm{KBr}, 8 \mathrm{~g} / \mathrm{L}$ of $\mathrm{Fe}_{2}\left(\mathrm{SO}_{4}\right)_{3} \cdot 4 \mathrm{H}_{2} \mathrm{O}$ dissolved in $750 \mathrm{~mL}$ natural seawater and $250 \mathrm{~mL}$ of distilled water at $25^{\circ} \mathrm{C}$ with shaking at $\left.150 \mathrm{rpm}\right)$. After seven days cultivation, the aqueous layer ( $\left.1 \mathrm{~L}\right)$ was extracted with an equal volume of ethyl acetate (EtOAc). The EtOAc-soluble layers were then combined and concentrated under reduced pressure to yield $1.5 \mathrm{~g}$ Streptomyces sp. APmarine042 extracts.

\subsection{Isolation}

The $1.5 \mathrm{~g}$ Streptomyces. sp. APmarine 042 were fractionated via flash column chromatography on silica gel eluted with $\mathrm{CH}_{2} \mathrm{Cl}_{2} / \mathrm{CH}_{3} \mathrm{OH}(100 / 0,100 / 1,100 / 5,100 / 10,100 / 20,100 / 100$, and $0 / 100 v / v$, each of $200 \mathrm{~mL}$ ) to obtain eight sub-fractions (Fraction 1-Fraction 8). The fifth fraction (Fraction 4) was further fractionated by reversed-phase HPLC (Phenomenex Luna C-18 (2), $250 \times 100 \mathrm{~mm}, 2.0 \mathrm{~mL} / \mathrm{min}$, $5 \mu \mathrm{m}, 100 \AA, \mathrm{UV}=254 \mathrm{~nm}$ ) using an isocratic condition $50 \% \mathrm{CH}_{3} \mathrm{CN}$ in $\mathrm{H}_{2} \mathrm{O}$ to obtain sarmentosamide (17.0 mg).

Sarmentosamide (1): $[\alpha]_{\mathrm{D}}=-168^{\circ}\left(\mathrm{C} 0.05, \mathrm{CH}_{3} \mathrm{OH}\right) ;{ }^{1} \mathrm{H}$ NMR $\left(\mathrm{CD}_{3} \mathrm{OD}, 300 \mathrm{MHz}\right): \delta_{\mathrm{H}} 7.43$ $(1 \mathrm{H}, \mathrm{dd}, J=15.1,11.4 \mathrm{~Hz}, \mathrm{H}-4), 6.42(1 \mathrm{H}, \mathrm{dd}, J=11.8,11.4 \mathrm{~Hz}, \mathrm{H}-3), 6.27,\left(1 \mathrm{H}, \mathrm{dq}, J=8.8,1.5 \mathrm{~Hz}, \mathrm{H}-3^{\prime}\right)$, $6.01(1 \mathrm{H}, \mathrm{qd}, J=15.1,6.8 \mathrm{~Hz}, \mathrm{H}-5), 5.59(\mathrm{dd}, J=11.8,0.7 \mathrm{~Hz}, \mathrm{H}-2), 4.80\left(\mathrm{~m}, \mathrm{H}-2^{\prime}\right), \delta_{\mathrm{H}} 1.95\left(\mathrm{~m}, \mathrm{H}-6^{\prime}\right)$, $1.85(3 \mathrm{H}, \mathrm{dd}, J=6.8,1.7 \mathrm{~Hz}, \mathrm{H}-6), 1.26\left(3 \mathrm{H}, \mathrm{d}, J=7.0 \mathrm{~Hz}, \mathrm{H}-1^{\prime}\right) ;{ }^{13} \mathrm{C}$ NMR $\left(150 \mathrm{MHz}, \mathrm{CD}_{3} \mathrm{OD}\right): \delta_{\mathrm{C}}$ 172.6 (qC, C-5'), 166.8 (qC, C-1), $141.2(\mathrm{CH}, \mathrm{C}-3), 137.7\left(\mathrm{CH}, \mathrm{C}-3^{\prime}\right), 137.6(\mathrm{CH}, \mathrm{C}-5), 130.9$ (qC, C-4'), $128.9(\mathrm{CH}, \mathrm{C}-4), 117.8(\mathrm{CH}, \mathrm{C}-2), 42.9\left(\mathrm{CH}, \mathrm{C}-2^{\prime}\right), 19.2\left(\mathrm{CH}_{3}, \mathrm{C}-1^{\prime}\right), 17.3\left(\mathrm{CH}_{3}, \mathrm{C}-6\right), 11.9\left(\mathrm{CH}_{3}, \mathrm{C}-6^{\prime}\right)$; LR-MS $m / z: 223.14[\mathrm{M}+\mathrm{H}]^{+}$.

\subsection{Cell Culture and Viability Assay}

Normal human dermal fibroblasts, neonatal (NHDFs), and human foreskin fibroblast cell line (Hs68) were purchased from Thermo Fisher Scientific (\#C-004 - 5C, Waltham, MA, USA) and American Type Culture Collection (\#CRL-1635, Manassas, VA, USA), respectively, and cultured in Dulbecco's modified Eagle's medium (DMEM, \#12-604F, Lonza, Walkersville, MD, USA) containing $10 \%$ fetal bovine serum (\#16000-044, Thermo Fisher Scientific), $100 \mathrm{U} / \mathrm{mL}$ potassium penicillin, and $100 \mathrm{mg} / \mathrm{mL}$ streptomycin sulfate (\#17 - 602E, Lonza) at $37^{\circ} \mathrm{C}$ in a humidified $5 \% \mathrm{CO}_{2}$ incubator. NHDFs were treated with serial sarmentosamide concentrations for $24 \mathrm{~h}$, after which the CCK-8 reagent (Dojindo Bio., Japan) was used to quantify cell viability according to the manufacturer's instructions ( $n=4$ per group).

\subsection{MMP-1 ELISA (Enzyme-Linked Immunosorbent Assay)}

NHDFs were pretreated with serum-free DMEM media for $18 \mathrm{~h}$, then exposed to $25 \mathrm{~mJ} / \mathrm{cm}^{2}$ UVB (average intensity: $2.7 \mathrm{~mJ} / \mathrm{cm}^{2}$ ) or treated with $20 \mathrm{ng} / \mathrm{mL}$ of TNF $\alpha$ and then co-treated with sarmentosamide at the different concentrations $(2.5,5,10 \mu \mathrm{g} / \mathrm{mL})$ in a serum-free DMEM media for an additional $48 \mathrm{~h}$. The amounts of secreted MMP-1 in the culture medium were quantified by an MMP-1 ELISA kit (R\&D system, \#DY901) according to the manufacturer's protocol. The final MMP-1 secretion results were normalized to the protein amounts in whole cell lysates, which were measured by a BCA protein quantification assay ( $n=3$ per group). 


\subsection{Western Blots}

Cell lysates aliquots were subjected to western blot assay as previously described [3]. Membranes were incubated with specific antibodies against JNK (\#9252, Cell Signaling Technology, Beverly, MA, USA), p-JNK (\#9251s), ERK (\#4695 s), p-ERK (4370 s), p38 (\#9212 s), p-p38 (\#4511 s), and $\beta$-actin (\#sc-1616, Santa Cruz Biotechnology, Dallas, TX, USA) in Tris-buffered saline (TBS) buffer containing $5 \%$ bovine serum albumin (BSA) and $0.1 \%$ Tween- 20 at $4{ }^{\circ} \mathrm{C}$ overnight. After washing, the membranes were allowed to react with peroxidase-conjugated secondary antibodies in TBS buffer containing $5 \%$ BSA and $0.1 \%$ Tween-20 at room temperature for $1 \mathrm{~h}$. Chemiluminescent signals were detected with an enhanced chemiluminescence (ECL) substrate (\#RPN2232, GE Healthcare, UK) and visualized with a chemiluminescence detection device (Fuji Film, Tokyo, Japan).

\subsection{DPPH Radical Scavenging Assay}

The 2,2-diphenyl-1-picrylhydrazyl (DPPH) was purchased from Sigma Aldrich (\#D9132). The DPPH radical scavenging assay was performed according to the previous reports with minor modification [14]. A total of $100 \mu \mathrm{M}$ of DPPH solution was freshly prepared with $100 \%$ ethanol. Then, $10 \mu \mathrm{L}$ of sarmentosamide solutions at the different concentrations were loaded onto 96-well plates, followed by $190 \mu \mathrm{L}$ of the DPPH solution. The 96-well plates were then incubated in a dark chamber at $37^{\circ} \mathrm{C}$ for $30 \mathrm{~min}$. Absorbances were then measured at $517 \mathrm{~nm}$ with a microplate reader (Biotek, Synergy HTX Multi-Mode Reader). DPPH radical scavenging activity was calculated with the following formula:

$$
\text { DPPH radical scavenging activity }(\%)=\frac{\text { Abs517nm of control }- \text { Abs517nm of sample }}{\text { Abs517nm of control }} \times 100
$$

where Abs517nm of control is the absorbance of the $190 \mu \mathrm{L}$ of DPPH mixed with $10 \mu \mathrm{L}$ of ethanol solution, and Abs517nm of sample is absorbance of the $190 \mu \mathrm{L}$ of DPPH mixed with $10 \mu \mathrm{L}$ of sarmentosamide solution.

\section{Conclusions}

In conclusion, an extract library of 250 marine microorganisms was screened to identify novel anti-aging compounds, of which one active Streptomyces sp. APmarine042 extract was selected. We then characterized the chemical structure of an active compound in the Streptomyces sp. APmarine042 extract using 1D and 2D NMR spectra and identified the compounds as sarmentosamide. Furthermore, we demonstrated that sarmentosamide significantly reduced UVB-induced MMP-1 expression and secretion in NHDFs by inhibiting ERK and JNK phosphorylation. Moreover, we confirmed that sarmentosamide decreased TNF $\alpha$-induced MMP-1 secretion in NHDFs and assessed its free-radical scavenging activity via the DPPH assay. Our results indicated that sarmentosamide could be a promising skin anti-aging agent that acts via the downregulation of MMP-1 expression.

Supplementary Materials: The following are available online at http://www.mdpi.com/1660-3397/18/9/463/s1, Figure S1: ${ }^{1} \mathrm{H}$ NMR spectrum $\left(300 \mathrm{MHz}, \mathrm{CD}_{3} \mathrm{OD}\right)$ of sarmentosamide, Figure S2: ${ }^{13} \mathrm{C}$ NMR spectrum $(150 \mathrm{MHz}$, $\mathrm{CD}_{3} \mathrm{OD}$ ) of sarmentosamide.

Author Contributions: E.-Y.L. and J.Y. isolated the compound and elucidated the chemical structure. E.-S.L. performed bioassays and mechanism study. A.H. did large culture and extraction. J.K. was the project leader for bioassay and analysis. S.-J.N. was the project leader for guiding the experiments of chemical analysis. All authors have read and agree to the published version of the manuscript.

Funding: The present study was supported by the Marine Biotechnology Program funded by the Ministry of Oceans and Fisheries, Korea and a grant from the Amorepacific Corporation (grant No. SRT-01-R18E999005) within the Amorepacific Open Research Program.

Conflicts of Interest: The authors declare no conflict of interest. 


\section{References}

1. Vierkotter, A.; Schikowski, T.; Ranft, U.; Sugiri, D.; Matsui, M.; Kramer, U.; Krutmann, J. Airborne particle exposure and extrinsic skin aging. J. Investig. Dermatol. 2010, 130, 2719-2726. [CrossRef] [PubMed]

2. Fisher, G.J.; Kang, S.; Varani, J.; Bata-Csorgo, Z.; Wan, Y.; Datta, S.; Voorhees, J.J. Mechanisms of photoaging and chronological skin aging. Arch. Dermatol. 2002, 138, 1462-1470. [CrossRef] [PubMed]

3. Park, N.H.; Kang, Y.G.; Kim, S.H.; Bae, I.H.; Lee, S.H.; Kim, D.Y.; Hwang, J.S.; Kim, Y.J.; Lee, T.R.; Lee, E.S. Dehydroabietic Acid Induces Regeneration of Collagen Fibers in Ultraviolet B-Irradiated Human Dermal Fibroblasts and Skin Equivalents. Skin Pharmacol. Physiol. 2019, 32, 109-116. [CrossRef] [PubMed]

4. Schuch, A.P.; Moreno, N.C.; Schuch, N.J.; Menck, C.F.M.; Garcia, C.C.M. Sunlight damage to cellular DNA: Focus on oxidatively generated lesions. Free Radic. Biol. Med. 2017, 107, 110-124. [CrossRef] [PubMed]

5. Kammeyer, A.; Luiten, R.M. Oxidation events and skin aging. Ageing Res. Rev. 2015, 21, 16-29. [CrossRef] [PubMed]

6. Chung, J.H.; Seo, J.Y.; Choi, H.R.; Lee, M.K.; Youn, C.S.; Rhie, G.; Cho, K.H.; Kim, K.H.; Park, K.C.; Eun, H.C. Modulation of skin collagen metabolism in aged and photoaged human skin in vivo. J. Investig. Dermatol. 2001, 117, 1218-1224. [CrossRef] [PubMed]

7. Waldera Lupa, D.M.; Kalfalah, F.; Safferling, K.; Boukamp, P.; Poschmann, G.; Volpi, E.; Gotz-Rosch, C.; Bernerd, F.; Haag, L.; Huebenthal, U.; et al. Characterization of Skin Aging-Associated Secreted Proteins (SAASP) Produced by Dermal Fibroblasts Isolated from Intrinsically Aged Human Skin. J. Investig. Dermatol. 2015, 135, 1954-1968. [CrossRef] [PubMed]

8. Lee, C.S.; Bae, I.H.; Han, J.; Choi, G.Y.; Hwang, K.H.; Kim, D.H.; Yeom, M.H.; Park, Y.H.; Park, M. Compound K inhibits MMP-1 expression through suppression of c-Src-dependent ERK activation in TNF-alpha-stimulated dermal fibroblast. Exp. Dermatol. 2014, 23, 819-824. [CrossRef] [PubMed]

9. Kim, J.M.; Kim, S.Y.; Noh, E.M.; Song, H.K.; Lee, G.S.; Kwon, K.B.; Lee, Y.R. Reversine inhibits MMP-1 and MMP-3 expressions by suppressing of ROS/MAPK/AP-1 activation in UV-stimulated human keratinocytes and dermal fibroblasts. Exp. Dermatol. 2018, 27, 298-301. [CrossRef] [PubMed]

10. Kitani, S.; Tomio, A.; Srichaisupakit, A.; Daduang, R.; Intra, B.; Panbangred, W.; Oku, N.; Igarashi, Y.; Nihira, T. Sarmentosamide, a novel hexadienamide from Thai soil actinomycetes. Nat. Prod. Res. 2013, 27, 226-231. [CrossRef] [PubMed]

11. Circu, M.L.; Aw, T.Y. Reactive oxygen species, cellular redox systems, and apoptosis. Free Radic. Biol. Med. 2010, 48, 749-762. [CrossRef] [PubMed]

12. Lee, S.B.; Kim, J.J.; Kim, T.W.; Kim, B.S.; Lee, M.S.; Yoo, Y.D. Serum deprivation-induced reactive oxygen species production is mediated by Romo1. Apoptosis 2010, 15, 204-218. [CrossRef] [PubMed]

13. Blaser, H.; Dostert, C.; Mak, T.W.; Brenner, D. TNF and ROS Crosstalk in Inflammation. Trends Cell Biol. 2016, 26, 249-261. [CrossRef] [PubMed]

14. Chen, Y.; Huang, J.; Hu, J.; Yan, R.; Ma, X. Comparative study on the phytochemical profiles and cellular antioxidant activity of phenolics extracted from barley malts processed under different roasting temperatures. Food Funct. 2019, 10, 2176-2185. [CrossRef] [PubMed]

(C) 2020 by the authors. Licensee MDPI, Basel, Switzerland. This article is an open access article distributed under the terms and conditions of the Creative Commons Attribution (CC BY) license (http://creativecommons.org/licenses/by/4.0/). 